Revista de Ciencias Sociales - Número 63 (2013) - Páginas 113-143

Crítica al internalismo del positivismo penal

\title{
CRÍTICA AL INTERNALISMO DEL POSITIVISMO PENAL
}

CRITIC TO THE INTERNALISM OF PENAL LAW

\author{
LEODANIS TORRES BARRERO* \\ Universidad de Holguín, Cuba \\ ltorrest@ict.uho.edu.cu \\ YUNIER RAMIREZ CEDEÑO** \\ Universidad de Holguín, Cuba \\ yramirezc@ict.uho.edu.cu
}

\section{Resumen}

El positivismo jurídico es la fuente fundamental que nutre a la ciencia del Derecho Penal, expresado en una línea de conducta determinista, muy internalista, que pone en primer plano las conexiones lógicas de los conceptos jurídicos y confunde históricamente esta ciencia con las normas penales o dogmática penal. Se propone, frente al internalismo epistemológico iuspositivista, una antropología jurídico-penal. El rasgo distintivo del método

* Profesor principal de Historia del Pensamiento Político y de Historia General del Estado y el Derecho. Departamento de Filosofía de la Universidad de Holguín, Cuba. Artículo recibido el 29 de noviembre de 2013 y aceptado el 10 de diciembre de 2013.

** Profesor asistente de Filosofía y Sociedad. Departamento de Filosofía de la Universidad de Holguín, Cuba.

Revista de Ciencias Sociales - Número 63 (2013) - Universidad de Valparáíso - ISSN 0716-7725-Valparaíso, Chile 
antropológico es la centralidad del sujeto y su conciencia, el destino del hombre como centro de su reflexión iusfilosófica. La antropología jurídico-penal es una actividad epistémica, metodológica y axiológica, que suscita nuevos valores epistémicos y prácticos del sujeto cognoscente y el objeto hombre.

\title{
Palabras claves
} hombre.

Internalismo epistemológico iuspositivista, antropología jurídico-penal,

\begin{abstract}
Legal positivism is the ultimate source that nourishes the science of penal law, expressed in a line of very internalizing, deterministic response, which foregrounds the logical connections of the legal concepts, and confuses historically this science with criminal or dogmatic laws. Against the legal iupositivist epistemological internalism, a legal and criminal anthropology is proposed. The distinctive feature of the anthropological method is the centrality of the subject and his conscience; man's destiny as the center of iusphilosofy reflection. The criminal legal anthropology is an epistemic, methodological and axiological activity, which brings about new epistemic and practical values of the cognoscenti and the object man.
\end{abstract}

\section{Keywords}

Legal positivist epistemological internalism, legal and criminal anthropology, man.

\section{Introducción}

El acercamiento inicial a la estructura antropológica del Derecho Penal como problema de investigación tiene el objetivo de sentar las bases metodológicas y teóricas sobre las cuales investigar y exponer el tema. El criterio rector en cuanto a método es que este saber debe estudiarse a partir del diálogo que se produce entre la dinámica estructural y política del proceso histórico. Aquí se tienen en cuenta elementos ontológicos, normativos y lógico-estructurales presentes en el proceso de construcción teórica del Derecho Penal. La necesidad de continuar pensando el carácter histórico del Derecho abre la

Facultad de Derecho y Ciencias Sociales - Universidad de Valparaíso - Chile 
oportunidad de un discurso jurídico penal ajeno al tradicional normativista. Toda una serie de problemas histórico-jurídicos de dichos espacios están a la espera de ser tratados por la historiografía.

Un reto, entonces, es diferenciar y a la vez interrelacionar ciencia del Derecho Penal y dogmática penal como un presupuesto teórico y metodológico para poder comprender y determinar las limitaciones de las categorías universales con las que ha trabajado el pensamiento iuspositivista al respecto; porque en ello está imbricado el concepto que se defendió acerca de la naturaleza del sujeto. Esto obliga a una seria reflexión actual sobre la capacidad de sus presupuestos para proporcionar respuestas adecuadas y transformadoras de la complejidad de nuevas situaciones.

\section{Hacia una nueva epistemología: inclusión del sujeto y los valores}

El pensamiento iuspositivista se configura a partir de dos elementos clásicos: el filogenético, es decir, el origen de familia de las ideas. Todo pensamiento se basa en un grupo de ideas que existe con anterioridad. Esa es la filogenia del pensamiento como fuente teórica. El otro elemento es la ontogenia, que viene de origen propio, de desarrollo orgánico; es lo que vincula el pensamiento a la realidad histórica y a los problemas específicos que tiene el hombre. El método concilia esos dos elementos y elucida la estructura antropológica.

Deben situarse las fuentes teóricas, pero sin descuidar la conexión de ese pensamiento con la realidad concreta que, en definitiva, es la que le da vida y donde ejerce sus funciones sociales. Lo antropológico, en Derecho Penal, puede presentarse en dos dimensiones: es una mediación en la solución de conflictos por el lado de la intervención subjetiva, subsistiendo las partes en pugnas en el mismo estatus de conciliación y, de otro lado, entiende la subjetividad como actividad transformadora, donde el conflicto es visto como etapa límite de la escisión en la contradicción, la cual no se soluciona sino que genera soluciones que la superan, donde cada una de ellas sitúa al proceso en un estatus más alto del desarrollo. Las soluciones son expresiones de la diversidad que alcanza lo ideal antropológico en el momento de desencadenamiento de la contradicción. El internalismo epistemológico

Revista de Ciencias Sociales - Número 63 (2013) - Universidad de Valparáíso - ISSN 0716-7725-Valparáiso, Chile 
iuspositivista presta poca atención a la incidencia de los factores externos sobre el sujeto cognoscente y sobrevalora los factores internos, los lógicometodológicos supuestamente guían rectamente a la razón científica hacia la verdad. Excluye también los factores ideo-políticos del propio sujeto.

Esa diversidad avanza contradictoriamente hacia el conocimiento del hombre como objeto. La actividad práctica jurídica se inserta en las soluciones de la contradicción. Esta apreciación tiene una importancia decisiva para comprender por qué varios sujetos cognoscentes pueden enfrascarse en las soluciones de una misma contradicción correspondiente al objeto hombre. De tal forma, el planteamiento de una solución de la contradicción, por un pensador particular, es una solución de la contradicción de la época. La postura, interpretación y su inserción en la contradicción fundamental de la época puede considerarse el indicador fundamental para evaluar el carácter progresista o no de su obra teórica y práctica.

La intervención subjetiva en el mismo estatus de conciliación y la actividad transformadora al considerarse mediaciones en la solución de conflictos permiten la construcción de una jusfilosofía penal del hombre, una antropología jurídico-penal ${ }^{1}$, que provee una visión totalizadora y orgánica de la estructura de la actividad humana. Así, la antropología jurídico-penal no puede considerarse exclusivamente como una actividad epistémica y metodológica, sino también como actividad axiológica, es decir, interroga el deber ser del Derecho Penal, suscitando nuevos valores epistémicos y prácticos tanto del sujeto cognoscente como del objeto hombre. Exige el método jurídico antropológico una ordenada comprensión de su interrelación e integración a la vida social. Posee diversas dimensiones, entre ellas:

a) la dimensión teórico-metodológica: sistema de conocimientos coherentes, racionales y contrastados empíricamente. La antropología

1. Primeramente es necesario precisar que este término no equivale a la antropología jurídica, la cual es una disciplina de la antropología cultural o social, afianzada durante el siglo XIX y XX debido a las investigaciones de relevantes juristas y antropólogos como Henry Summer, John Mac Lennan, Edward B. Tylor, RadcliffeBrown, Roscoe Pound y Malinowski.

Facultad de Derecho y Ciencias Sociales - Universidad de Valparaíso - Chile 
jurídico- penal tiene un fundamento holístico, porque lo antropológico posee un valor extraordinario, desde el punto de vista teórico metodológico y práctico. En síntesis, es pensar el Derecho Penal en un proceso mediado por la praxis, donde lo ideal y lo material se convierten recíprocamente, en la construcción del conocimiento y la revelación de la eficacia, validez, vigencia y legitimidad del este Derecho, fundado en la realidad y elucida, a su vez, su dimensión tecnológica. Posibilita metodológicamente aprehender con sentido sistémico una racionalidad integradora de la intervención subjetiva y la actividad transformadora del hombre. Racionalidad abierta a la Teoría General del Derecho, la dogmática jurídica y la Sociología del Derecho, capaz de develar categorías y conceptos centrales y operativos cuya meta es la utilidad o eficacia, entre ellas: legitimidad social, seguridad jurídica, igualdad, regla social, obligatoriedad, operatividad de los enunciados jurídicos, cumplimiento del derecho positivo, valoración, coacción, sujeto o actor social, personalidad, fines sociales, sociabilidad, conceptos como validez y vigencia de la norma, etc, que en no pocas ocasiones, imbuidos por la herencia de la racionalidad positivista y normativista modernas, se han asumido en relación de antítesis absoluta; sin embargo, la comprensión del condicionamiento socioeconómico e ideológico de todo saber devela su unidad dialéctica.

b) la dimensión histórica: los procesos del pensamiento crítico en la búsqueda y transformación de los conocimientos, la actividad práctica investigativa tiene su terreno en condiciones concretas sociales, económicas, psicológicas, políticas, ideológicas, etc. Consiste en que el Derecho Penal es asumido críticamente, y con ello, la antropología jurídico- penal del hombre unifica en lo diverso las varias dimensiones que el sujeto teórico en su quehacer práctico - espiritual ha creado históricamente, es decir, las expresiones ontológica, lógica, gnoseológica, valorativa, praxiológica, comunicativa y normativa. Se entiende que el sujeto cognoscente debe de recurrir en alguna medida a las concepciones del Derecho: clásico (helénico), escolástico (medieval), racionalista moderno y la concepción positivista que comprende esencialmente la sociologista y normativista, para explicar las categorías con las que ha trabajado el pensamiento iusfilosófico y verlas ahora en una integración de saberes o de racionalidad abierta en función del hombre.

Revista de Ciencias Sociales - Número 63 (2013) - Universidad de Valparáíso - ISSN 0716-7725-Valparaíso, Chile 
c) la dimensión institucional y cultural: en lo más profundo es una actividad iusfilosófica normativa desde el punto de vista de la producción, del dominio y transformación del mundo humano o cultural, donde incluye necesariamente la difusión de la ciencia del Derecho Penal. La antropología jurídico-penal, a diferencia del determinismo jurídico ${ }^{2}$, no subordina el hombre a la norma jurídica. El cientificismo objetivista del positivismo penal erige una Ciencia del Derecho autónoma y autosuficiente. El antropologismo jurídico-penal, por el contrario, entiende el hombre y su existencia como un hecho de conciencia y objetos del Derecho Penal. El antropologismo jurídicopenal duda de la neutralidad iuspositivista y, reivindica la fuerza espiritual del hombre. El reduccionismo gnoseológico del positivismo penal excluye el sujeto epistémico de la propia investigación y reduce el Derecho Penal a solo norma. El antropologismo jurídico-penal incluye el sujeto de la ciencia a su reflexión iusfilosófica e indaga el lugar del Derecho Penal en la vida y destino del hombre para adquirir un contenido programático. Al método inductivo del positivismo penal sólo le interesa las conexiones lógicas de los conceptos jurídicos. El antropologismo jurídico-penal sustituye el logicismo normativista por la idea del Derecho, la intuición, el vitalismo jurídico y la praxis transformadora al plantearse un propósito deontológico presupuesto que implícitamente enriquece la concepción de legalidad.

La generación de soluciones que superan a la contradicción en un estatus más alto del desarrollo implica factores de carácter instrumental y externos social, cultural y psicológico previstos en esas dimensiones que le da sentido a lo antropológico. Se trata de la aludida interpretación y su inserción en la contradicción fundamental de la época, por ejemplo, ante un presupuesto normativista que se impone

2. El determinismo es un término muy común en el comercio de palabras. Existen diferentes formulaciones de determinismo: determinismo económico, determinismo biológico, determinismo naturalista, determinismo tecnológico, determinismo geográfico, determinismo de clases, etc. Todos pueden coincidir en determinadas posiciones. No es patrimonio exclusivo de un autor, más bien puede tomarse como una postura filosófica y científica universal que sostiene que todo acontecimiento económico, natural, incluyendo el pensamiento y acciones humanas, están determinados mecánicamente por la interrelación causa-efecto.

Facultad de Derecho y Ciencias Sociales - Universidad de Valparaíso - Chile 
verticalmente al hombre desde el poder la antropología jurídico-penal irrumpe en la tesis clásica del sistema jurídico como mera construcción escalonada de normas. Tesis que afirma que uno de los criterios de validez de esas normas es el criterio de legalidad: una norma es válida y pertenece al sistema jurídico, si es creada de conformidad con las normas superiores que disciplinan su creación tal como lo previó Kelsen en su Teoría Pura del Derecho3.

Es una definición que se aleja de los seudoproblemas, porque el sujeto cognoscente dejaría aclarado de qué forma las normas jurídicopenales afectarían a la ordenación o sistematización de un sector humano e incluso se desprendería una propuesta de criterios sobre la producción y aplicación de la dogmática penal. Lo antropológico se eleva al rango de correctivo legal y social con el cual la revisión del derecho positivo penal tiende hacia el ideal de justicia. Aquí rompe con el pragmatismo y el utilitarismo jurídicos que consideran una sociedad ordenada y justa cuando sus instituciones alcanzan el mayor peso neto de las utilidades individuales sumadas. La justicia no es una cuestión solamente teórica sino también práctica.

Una vez elaborada dicha definición, por el camino del pensamiento que conduce a la reproducción del objeto hombre, el sujeto cognoscente está en condiciones de determinar, argumentar, explicar y valorar el concepto antinormativista de Derecho Penal. Definición que constituye un aporte conceptual y tecnológico que posibilita mejor examinar la relación dogmática penal y cambio social y cambio social sin cambio de la dogmática penal desde una perspectiva holística o transdisciplinar; problemáticas confinadas en reiteradas ocasiones a los estudios meramente jurídico-sociológicos donde prevalecen el determinismo normativista y el reduccionismo gnoseológico.

La antropología jurídico-penal podría tomar el Derecho Penal no desde el objetivismo cientificista del positivismo sino como resolución de problemas prácticos y como tecnología en busca y utilización consciente de la ciencia aplicada mediante procedimientos o acciones orientadas al logro de determinados objetivos jurídicos, ya fuere el de

3. $\mathrm{Al}$ respecto véase a KELSEN, Hans: ¿Qué es la Teoría pura del Derecho? Fontamara, México, 1993. (Trad. de E. Garzón Valdés). Pág. 55.

Revista de Ciencias Sociales - Número 63 (2013) - Universidad de Valparáíso - ISSN 0716-7725-Valparáiso, Chile 
transformar, controlar o dominar la realidad, lo que la haría susceptible de juicio valorativo.

\section{La emergencia del binomio sujeto-objeto}

Es una exigencia metodológica imprescindible partir de la diferenciación del objeto de la realidad objetiva y el objeto reproducido por el sujeto epistémico, esto es, la construcción del objeto. Von Liszt intentó articular el Derecho Penal y la Criminología en una ciencia total del Derecho Penal. La totalidad debía conjugar la explicación jurídica y la inductiva de la Criminología desde el punto de vista funcional, si bien la separación metódica continuaba siendo una exigencia. El jurista de la dogmática penal incluiría en su labor la proyección de reformas del Derecho Penal.

Esa posición teórica encierra un círculo determinista que quiere expresar una modelación exacta como lenguaje rector del jurista. Los conceptos físicos o biológicos definen la acción típica, antijurídica y culpable. El legislador concreta, por su parte, los tipos delictivos en la Parte Especial. El jurista práctico no se agota en la dogmática clásica, además de la elaboración sistemática de los conceptos que sirven a la aplicación del derecho positivo proyecta la reforma del mismo, el cual se concibe neutralmente valorativo. De esta forma, la objetividad del tipo, determinado supuestamente por el hecho, no es otra cosa que el objetivismo cientificista que pregona la ciencia positivista. Este círculo positivista no se interroga la construcción del objeto. Realmente, para esta concepción, el objeto absoluto es la norma penal.

Prevalece la tendencia a identificar Derecho Penal y dogmática penal. El profesor cubano Renén Quirós Pírez acertadamente elabora un concepto de Derecho Penal, donde especifica su objeto de conocimiento: "El Derecho Penal constituye una rama específica del Derecho integrado por el sistema de conocimientos materializados en teorías, conceptos, juicios, postulados, categorías, principios y normas relacionadas con el objeto de su particular esfera cognoscitiva, o sea, el

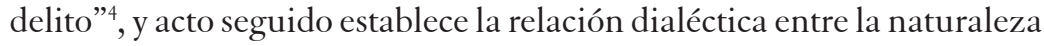

4. QUIRÓS PÍREZ, Renén: Manual de Derecho Penal, tomo I, Editorial Félix Varela, La Habana, 2006. Pág. 16.

Facultad de Derecho y Ciencias Sociales - Universidad de Valparaíso - Chile 
del delito y la esencia de las normas penales. Se advierte que la sociedad es previa a la norma y que esta tipifica el hecho, porque el "delito [...] resulta un hecho que se produce en el terreno de la vida social, de la realidad objetiva [...]. La norma jurídica no es más que la expresión formal de ciertas relaciones sociales" ${ }^{5}$. Sin embargo, incurre en una contradicción epistémica en una de sus conclusiones, cuando dice que "[...] el Derecho Penal representa la afirmación jurídica de necesidades materiales de la sociedad [...]"6.

De ese modo el Derecho Penal es norma penal y, aunque no se quiera, el itinerario sujeto de la ciencia-objeto del conocimiento se irrumpe arbitrariamente. La ciencia, en este caso, no puede ser afirmación jurídica de una necesidad, más bien tiene entre sus funciones afirmar la necesidad de una nueva norma penal o la no necesidad de una determinada norma penal vigente. El citado profesor sí mantiene una postura epistémicamente correcta cuando señala que "[...] las necesidades materiales de la sociedad [...] quedan vinculadas con la definición, en normas jurídicas, de aquellas conductas [...] de elevado peligro"”.

El sistema de conocimiento que erige el Derecho Penal sobre el delito y, la norma penal, no son lo mismo. La no distinción sólo opera en el pensamiento. De tal forma, el sujeto de la ciencia queda atrapado en la lógica iuspositivista. El cientificismo objetivista encierra la ciencia en la norma penal y observa a esta como una arista normativa de aquella. Así, la norma penal es objeto y ciencia en sí misma a la vez. La antinomia queda expresada en el referido autor al afirmar que "[...] es cierto que el jurista debe estudiar el aspecto normativo de esta rama, o sea, lo relacionado con la inteligencia y exposición de las normas jurídicopenales"
5. Ídem.
6. Ídem.
7. Ídem.
8. Ídem.

Revista de Ciencias Sociales - Número 63 (2013) - Universidad de Valparáíso - ISSN 0716-7725-Valparáiso, Chile 
La ciencia del Derecho Penal y las normas penales son formas de la conciencia social, pero no devienen idénticas. El contenido de ambas son las relaciones sociales. La norma jurídico-penal es expresión formal de ciertas relaciones sociales tal como lo dice el propio Quirós Pírez. No obstante, es necesario detenerse nuevamente en este autor: El Derecho Penal [...] no regula directamente relaciones sociales; su contenido se halla condicionado por la tarea específica que tiene asignada [...], la prohibición de aquellos actos que resultan peligrosos para el régimen de relaciones sociales. De este modo, el Derecho Penal deviene mecanismo de coerción indirecto, por cuanto la acción de sus normas se dirige a la protección del orden social ${ }^{9}$.

Existe una verdad objetiva en ese planteamiento. Si el hecho que se origina en el mundo de las relaciones sociales no es prohibido penalmente, entonces no puede constituir contenido del Derecho Penal. Ahora bien, el profesor no advierte que el hecho prohibido es contenido de las normas jurídico-penales, que en realidad es la dogmática penal. Esta es objeto de conocimiento del Derecho Penal, que es tanto como decir, ciencia del Derecho Penal. La prohibición media entre el hecho y la ciencia del Derecho Penal. Y, al mediar, convierte el hecho en delito, por tanto en objeto del Derecho Penal. Se concluye que la dogmática condiciona el delito como su contenido y lo eleva a la categoría de objeto del Derecho Penal. La dogmática y el delito son inseparables. Esto es la unidad de contenido (hecho) y forma (norma penal). El hecho cualificado o tipificado (en técnica jurídica) es, a su vez, contenido del propio Derecho Penal.

La profesora cubana Guadalupe Ramos Smith afirma que “[...] el Derecho Penal puede ser analizado en su doble aspecto de disciplina científica y de ley positiva" ${ }^{10}$. No da cuenta de las problemáticas que puede acarrear obviar la necesaria diferenciación ya aludida. Sin embargo, se comparte su criterio en cuanto a que "[...] el Derecho Penal como ciencia plasma sus conceptos, categorías e instituciones en

\section{Ibíd. Pág.18.}

10. RAMOS SMITH, Guadalupe: Derecho Penal. Parte General I, Facultad de Derecho, Universidad de La Habana, 1985. Pág. 62.

Facultad de Derecho y Ciencias Sociales - Universidad de Valparaíso - Chile 
forma sistematizada en un Código Penal [...]"11 . Al parecer, la profesora sigue a Von Liszt, quien entre otros aspectos, aporta al Derecho Penal el análisis de la relación entre el sujeto de la dogmática penal o jurista práctico y el legislador. La interrelación ciencia del Derecho Penaldogmática penal-delito, encierra en principio, a esos sujetos, los cuales aparecen clarificados.

La mencionada prohibición mediadora entre el hecho y el Derecho Penal condiciona una conceptualización que identifica en la diferencia las diversas acciones y omisiones delictivas aprobadas abstractamente por el legislador, es decir, la dogmática penal. Semejante identificación en la diferencia recibe el nombre de tipos penales en técnica jurídica alemana. Esto sucede, porque cuando el concepto se sistematiza en un Código Penal se trueca en técnica con el fin de ser aplicada. La acción u omisión es delito si es un hecho típico "[...] entendiéndose por tal el que incluye todos los elementos que integran la figura creada por la ley, el que reproduce el esquema legal [...]”12.

La concepción dogmática formal del delito se ha impuesto en la dogmática penal y, subyace no pocas veces, en la ciencia actual del Derecho Penal. La teoría de Karl Binding es la base primigenia que identifica consecuentemente dogmática y Derecho Penal. El periodo 1906-1933 no se entiende sin él. En 1872 aparece su Teoría de las normas, la cual emprende la elaboración dogmática del concepto de delito. Binding se centró en los elementos constitutivos del delito como ente jurídico. A partir de los conceptos de norma y ley en sentido estricto, los dogmáticos alemanes del periodo señalado conceptualizaron el delito. Desde entonces, todo concepto del mismo encierra, de una forma u otra, los términos de antijuricidad y tipicidad.

Ese autor desarrolla la llamada teoría de las normas, y su coterráneo Ernest von Beling la teoría del tipo. Las categorías fundamentales de la labor de Binding son la conducta delictiva y la ley penal. Diferencia la norma de la ley penal. La conducta delictiva trasgrede la norma y no la ley en sí. Las normas son prohibiciones o

\footnotetext{
11. Ídem.

12. Ibíd. Pág. 335.
}

Revista de Ciencias Sociales - Número 63 (2013) - Universidad de Valparáíso - ISSN 0716-7725-Valparáiso, Chile 
mandatos de acciones y, se extraen del tipo; enfatiza además que, la norma tiene como objeto la ilicitud de los individuos (excluyendo a los alienados y a los niños), entonces la ilicitud es siempre culpable y, no admite el injusto objetivo. La conminación sólo es esencial para la ley penal. La norma tiene como fin la obediencia del derecho, en tanto que la ley penal busca la pena. Las normas son para Binding presupuesto de la ley penal pues permanecen con fuerza y autoridad por sí mismas.

Por su parte Ernest von Beling, partiendo de los principios de legalidad y reserva, sostuvo que el Derecho Penal regula o atrapa sólo algunas conductas humanas que están específicamente determinadas, y es por eso que tales conductas deben estar descriptas en tipos y no en vagas enunciaciones, sosteniendo que la tipicidad es la adecuación de la conducta en el caso concreto. En una primera enunciación de sus ideas en 1906 dice que el tipo es independiente de la antijuridicidad y la culpabilidad. Reformula en 1930 la teoría del tipo mostrando las relaciones existentes entre tales elementos, es decir que la conducta debe acomodarse al delito tipo, pero además, debe ser antijurídica y culpable según esa tipicidad; entonces define el delito como "una acción típicamente antijurídica y correspondientemente culpable"13.

El concepto dogmático del delito es positivista por excelencia. Está dominado por el hecho. Este es considerado un dato. El derecho positivo - siguiendo esta lógica - es un dato y premisa indispensable en la definición del delito. La concepción dogmático-formal del delito reserva el objetivismo subjetivista y, consecuente con él, se atribuye un sector de lo real que le correspondería como propio. Mutila el pensamiento, porque el concepto de delito ya no es una construcción teórica, sino resultado de la observación de una norma jurídico-penal. Sólo le interesa a la dogmática la descripción del hecho que es el delito. La descripción comprobaría sus elementos estructurales que permiten la existencia de la pena.

La ciencia del Derecho Penal se atrinchera en la supuesta neutralidad científica dada una reiterada autosuficiencia que pregona al delito como objeto aislado y específico. Máximos representantes de

13. BELING, Ernst von: Esquema de Derecho Penal. La teoría del delito-tipo, Bs. As. Depalma, 1944. (Trad. S. Soler). Pág. 122.

Facultad de Derecho y Ciencias Sociales - Universidad de Valparaíso - Chile 
la concepción dogmático- formal del delito son Von Liszt y Beling. Concretamente, reducen el Derecho Penal a norma penal y ley penal. Antes se dijo que la prohibición media entre el hecho y la ciencia del Derecho Penal, y que el hecho convertido en delito es objeto y contenido a su vez de esta, aunque parezca lo contario Von Liszt y Beling se alejan de dicho fundamento. El reduccionismo fenomenológico positivista, del cual no da cuenta la historiografía tradicional penal sustenta el carácter formal de la definición de delito. La estructura del delito se erige en presupuesto de su naturaleza jurídica, así es un hecho, un dato creado para la teoría y por la cual fue creado.

La relación sujeto de la ciencia-objeto del conocimiento es un principio metodológico imprescindible en cualquier crítica teórica. Este trabajo no rechaza las categorías de tipicidad y antijuricidad más bien plantea la necesidad de desentrañar el análisis lógico-jurídico reduccionista en la que han sido atrapadas la dogmática y la ciencia del Derecho Penal. Son prácticamente las mismas definiciones tanto la concepción dogmático-formal del delito de Ernesto Beling, que plantea la tipicidad como descripción objetiva, la de Max Ernesto Mayer donde la tipicidad es el más importante índice de la antijuricidad de una conducta, la de Von Liszt que define el delito como el acto culpable, antijurídico y sancionado con una pena, la de Edmundo Mezger que sostiene que la tipicidad expresa por sí misma la antijuricidad y, en este sentido, el delito es la acción típicamente antijurídica y culpable; por último, la de Francisco de Asis Toledo define el delito como la acción típica, ilícita y culpable. La estructura normativa del delito determina, en estos casos, su naturaleza jurídica. El sector de lo jurídico aparece como un hecho comprobable por la empiria. La dogmática penal y el Derecho Penal que, para este caso es presentado como lo mismo, desplaza el sujeto y, en su lugar, pone la norma penal y la ley penal, las cuales definen el delito como ente jurídico abstracto.

La inobservancia del referido principio metodológico no distingue la ciencia del Derecho Penal de la dogmática penal. En busca de un objeto exclusivo gravita hacia una supuesta neutralidad. El objeto real (hecho delictivo) definiría a la dogmática penal como ciencia autónoma. Frente a esta el objeto real aparece como objeto científico construido. El sentido común del sujeto dogmático se orienta hacia el

Revista de Ciencias Sociales - Número 63 (2013) - Universidad de Valparáíso - ISSN 0716-7725-Valparaíso, Chile 
delito, porque lo percibe real y concreto. La regulación normativa del hecho es el Derecho que sería un supuesto tangible y efectivo. Parece certero iniciar una exposición del Derecho Penal por la norma penal y por la ley, su única fuente o fuente principal, luego se impone fijar la estructura de la norma penal, sus funciones, así como el poder del Estado al respecto: el ius puniendi, etc. Con arreglo a esta exposición normativista de las ideas no hay otra posibilidad que emprender luego la labor teórica en torno al delito tal como sucede comúnmente. El supuesto efectivo, en este caso, es el Derecho Penal o dogmática penal. Las determinaciones teóricas del objeto ya nacen confusas y carecen de libertad. El concepto de delito y de Derecho Penal constituye así un fin y no un momento necesario. El pensamiento teórico, por el contrario, debe reproducir el objeto no a partir de una representación caótica de abstracciones en torno a la dogmática penal sino reproducir el objeto como totalidad de sus determinaciones.

Las múltiples determinaciones no son más que las definiciones del pensamiento, esto es, de la ciencia del Derecho Penal en torno a su objeto, de un lado y, de otro, las definiciones del pensamiento sobre el propio Derecho Penal. El camino seguido históricamente por la ciencia del Derecho Penal llegó hasta las determinaciones más simples, no todas exentas de subjetivismo. No se aportará aquí en la conceptualización de las mismas, más bien la tesis que sostiene este trabajo es de que hay mayor interés en el modo en que tiene que configurarse la ciencia del Derecho Penal y no tanto si las categorías trabajadas existen o no en la realidad.

La dogmática se erigió es ciencia neutral, con un objeto específico y un lenguaje que busca las conexiones lógicas de los elementos constitutivos del concepto jurídico del delito. Excluye de esta forma, el elemento material-clasista del hecho delictivo o peligrosidad social del hecho. Los elementos conceptuales del delito para la concepción dogmático-formal constituyen el hecho mismo. La formulación jurídica es el supuesto referente objetivo. Puede quedar esquematizada de la siguiente forma:

Facultad de Derecho y Ciencias Sociales - Universidad de Valparaíso - Chile 


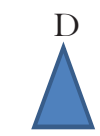

A-B-C

Donde:

A es el autor identificado con el elemento subjetivo.

$\mathrm{B}$ es la norma penal identificada con el elemento normativo (antijuricidad y tipicidad).

C es la ley penal identificada con la punibilidad o sanción.

El común de los teóricos posteriores a Beling y Mayer unifica el elemento normativo en la ley.

D es una ley superior sin la cual, evidentemente, no puede existir la ley penal inferior, o sea, se trata del criterio de validez.

Podría pensarse que el hecho queda fuera del esquema, pero es un cuarto elemento subsumido en la ley penal identificado como elemento objetivo: conducta, resultado y causalidad entre ambos. La peligrosidad social no es asumida como criterio de objetividad cuando la prohibición convierte el hecho en delito. Técnicamente, la concepción dogmático-formal del delito observa el estado peligroso como contenido de la responsabilidad penal y no el hecho que resulta socialmente peligroso.

Anteriormente se precisó que el hecho constitutivo de delito es contenido material de la dogmática, porque es un hecho que se produce en el universo de las relaciones sociales. El análisis dogmático-formal del delito, por su parte, se centra en el individuo en tanto es subordinado a la ley penal, según su peligrosidad en ocasión de un delito. Realmente la norma admite un déficit antropológico cuando desplaza al sujeto. Cualquiera de los conceptos dogmático-formales del delito antes referidos exalta ocultamente la peligrosidad del sujeto, y la convierte en el referente supuestamente objetivo para determinar el tipo y la sanción imponible. Este fundamento positivista es pos-Ferri, quien afirmó que: [...] cuando se admite, como no puede ser de otra manera, que los fenómenos jurídicos no son sino fenómenos sociales, porque derecho y sociedad son términos inseparables y equivalentes, se hace evidente de

Revista de Ciencias Sociales - Número 63 (2013) - Universidad de Valparáíso - ISSN 0716-7725-Valparaíso, Chile 
inmediato la artificialidad de aquella separación entre una ciencia que estudia el delito como fenómeno jurídico y otra que lo estudie como fenómeno social — por lo que- es absurda la pretensión de separar el estudio del aspecto material y social del aspecto jurídico ${ }^{14}$.

El concepto dogmático-formal del delito es opuesto a la valoración que Ferri hace sobre la peligrosidad social del delincuente. Si bien coinciden en algún momento en las características atávicas del delincuente, el positivismo penal de Ferri se concentró en los factores bio-sociológicos, lo que explica su afirmación anterior. La primera observa el estado peligroso como contenido de la responsabilidad penal. Ferri se centra en el hecho que resulta socialmente peligroso y, por ende, en la responsabilidad que tiene la sociedad hacia el que delinque.

El carácter autónomo y neutral atribuido a la dogmática penal (identificada con el Derecho Penal por los normativistas) también la alejó de la sociología positivista de Durkheim. El hecho, que para Durkheim es una cosa, pero construida mentalmente y opuesta a las evidencias del sentido común, es para la concepción dogmática lo dado, lo fáctico, lo concreto. Durkheim consideró en 1895 que el hecho [...] es toda cosa objeto de conocimiento que no es naturalmente compenetrable a la inteligencia [...]. Tratar hechos de un cierto orden como cosas no es, pues, clasificarlos en tal o cual categoría de lo real; es observar con ellos una determinada actitud mental $[\ldots]^{15}$.

Con ello la ciencia se construye, porque construye su objeto y se interroga la construcción del mismo:

Sin duda, la idea que nos forjamos de las prácticas colectivas, de lo que son o de lo que deben ser, es un factor de desarrollo. Pero esta idea misma es un hecho que para ser convenientemente determinado debe también ser estudiado objetivamente. Y esto porque lo que importa conocer no es la manera como tal o cual pensador se representa individualmente una institución, sino la concepción que de ella se ha formado el grupo: esta concepción es la única socialmente eficaz ${ }^{16}$.

14. FERRI, Enrico: Principios de derecho criminal, (s/p/i), 1928. Pág. 75.

15. DURKHEIM, Emile: Las reglas del método sociológico, Editorial A Kal, Madrid, 1997. Pág. 21.

16. Ibíd. Pág. 23.

Facultad de Derecho y Ciencias Sociales - Universidad de Valparaíso - Chile 


\section{Perspectiva crítica del binomio teoría -praxis}

La peligrosidad social es la categoría cardinal para determinar el carácter objetivo o no del sistema categorial de la dogmática penal. Debe ser asumida para dar un paso importante en la argumentación de los fundamentos teórico-metodológicos necesarios de una ciencia del Derecho Penal crítica y superadora de los enfoques normativistas. En principio se quiere junto a Alessandro Baratta:

[...] una ciencia social comprometida en la transformación del propio objeto, es decir, una ciencia social en donde la interpretación teórica de la realidad sea dialécticamente mediata del interés y la acción para la transformación de la realidad, en el sentido de la resolución positiva de las contradicciones que constituyen la lógica del movimiento objetivo de la misma y de la satisfacción de necesidades individuales y sociales en su contenido históricamente determinado ${ }^{17}$.

Una ciencia del Derecho Penal consciente del papel de la peligrosidad social puede ser guía de la dogmática jurídica. Se hace imprescindible reiterar que la peligrosidad social determina el delito. La prohibición condiciona el hecho y lo convierte en delito. La peligrosidad social, entonces, determina el hecho delictuoso y, por consecuencia, a la dogmática penal. La peligrosidad social como una de las determinaciones del pensamiento objetivo tiene una naturaleza mediadora porque su fundamento último es el binomio teoría-praxis. Este debe caracterizar el modelo antiformalista y antropológico de la ciencia del Derecho Penal.

La finalidad positivista del tipo penal se limita a la realización del principio de nulla poena sine lege y, en consecuencia, no logra salir del círculo dogmático-formal del delito. En verdad, desde un fundamento antropológico de centralidad del objeto hombre, el legislador habría practicado en la Parte Especial una concreción de la peligrosidad social que fundamentase la prohibición y, por consecuencia, la necesidad de pena, la cual no puede ser desproporcionada al hecho ni a la peligrosidad.

17. BARATTA, Alessandro: Criminología crítica y crítica del Derecho Penal. Introducción a la sociología jurídico-penal, Siglo XXI Editores Argentina s. a. Buenos Aires, 2004. Pág. 163.

Revista de Ciencias Sociales - Número 63 (2013) - Universidad de Valparáíso - ISSN 0716-7725-Valparáiso, Chile 
La dogmática penal deviene en un subsistema cerrado de control social, porque la peligrosidad social no es presupuesto que asuman realmente. En efecto, las funciones de tutela de la dogmática penal con respecto a las prohibiciones consideran que las penas son instrumentos idóneos, al menos en parte, para hacer respetar las prohibiciones, es decir, en la medida en que se acoja el paradigma general preventivo de la función de las penas. El problema es que la pena se aleja de lo que los ciudadanos o la sociedad entienden como peligrosidad social. La sociedad es previa a cualquier norma penal, sin embargo, esta puede no ajustarse a la realidad e imponerse verticalmente sobre los sujetos. Los criterios de validez serían los del normativismo jurídico conservador. La legitimidad se decidiría en el círculo ritual dogmático penal. La concepción dogmática formal del delito salió históricamente vencedora. El elemento material clasista del delito es rechazado en lo más profundo del pensamiento penalista.

No se trata, pues, de introducir arbitrariamente todos los factores posibles que podrían intervenir en la comprensión del hecho delictivo, sino de crear modelos multicausales que tengan en consideración las vinculaciones de distinto signo que se producen entre el ámbito social, jurídico y político. De lo macrosocial debe pasarse al aspecto concreto de la norma penal. Esta, siguiendo a Atienza, como toda otra norma jurídica es una estructura que implica un determinado nivel de racionalidad teórica, representativa, pero de un tipo tal que es imposible segregarla del plano ejerciativo de la acción. La norma es representación racional de una cierta frecuencia práctica de acción frente a otras "[...] pues cuando se dice que una norma es una razón para la acción se están diciendo, en realidad, dos cosas distintas: que una norma es una guía de comportamiento y, también que es un criterio de valoración (esto es de justificación o de crítica) de la conducta"18.

Desde una perspectiva crítica el binomio teoría-praxis tendrá que ser interpretado como una dicotomía no absoluta, sino conjugada. Necesariamente debe recurrirse a conceptos epistemológicos que aludan al grado de objetividad de dichas formas de racionalidad. El análisis

18. ATIENZA RUIZ, José: Las piezas del Derecho. Teoría de los enunciados jurídicos, Ariel, Barcelona, 1996. Pág.131.

Facultad de Derecho y Ciencias Sociales - Universidad de Valparaíso - Chile 
epistemológico de la peligrosidad social la ubica en lo macrosocial y la norma penal es lo concreto, porque es síntesis de ella. La ciencia del Derecho Penal se dirige a un espacio práctico organizado por las propias normas jurídicas en cuanto estructuradoras de la fenomenología práctica jurídica y de las instituciones políticas. Si la prohibición media entre el hecho y la ciencia del Derecho Penal, no es menos cierto que hay mediaciones entramadas en ese proceso. En la construcción de lo que se entiende por Derecho impera la necesidad de comprender según Bulté “[...] las complejísimas mediaciones de todo tipo, verbi gratia, ideas políticas, filosóficas, tradiciones históricas de todo tipo, condicionamientos técnicos jurídicos, prácticas institucionales, etcétera" ${ }^{19}$.

La adopción de la estructuración normativa como nivel teórico esencial de explicación de la ciencia del Derecho Penal no basta para considerarla como ciencia. Aquí hay una limitación potencial: se apela a la forma de las normas penales y no a su contenido. La ciencia del Derecho Penal en definitiva tiende a la elaboración de un concepto normativista del Derecho. El alcance de la racionalidad de la ciencia del Derecho Penal según el modelo positivista se agota en el ámbito de las relaciones jurídico-normativas.

La crítica anterior indica, además, el reconocimiento de una situación conflictiva como base del sujeto epistémico, dicha situación es una realidad que necesita ser superada por la subjetividad como actividad transformadora, donde el conflicto es visto como etapa límite de la escisión en la contradicción. La complejidad de la realidad social exige una visión sistémica de la ciencia del Derecho Penal y la dogmática penal como su objeto, en los cuales múltiples aspectos estructurales, relacionales y funcionales explican mejor las funciones básicas de esta: la seguridad jurídica y la igualdad. Los argumentos, categorías, fines, funciones y principios básicos del pensamiento sistémico jurídico como son la retroalimentación, el entorno, reintegración del sujeto, etc, que tienen a la peligrosidad social de base trascienden el mero enfoque positivista de vulneración de la norma-aplicación de la sanción. El sujeto de la ciencia del Derecho Penal, el sujeto de la política criminal y el

19. FERNÁNDEZ BULTÉ, Julio: Filosofía del Derecho, Editorial Félix Varela, La Habana, 2003. pág. 289.

Revista de Ciencias Sociales - Número 63 (2013) - Universidad de Valparáíso - ISSN 0716-7725-Valparáiso, Chile 
sujeto de la dogmática penal deben hacer suya la ciencia sistémica, para de acuerdo a ella desencadenar el ejercicio del control social, la aplicación de la pena y emisión de leyes.

La ciencia del Derecho penal debe problematizar la propia jurisprudencia y no diluir el objeto real en el objeto penal. Así podrá visualizar posibles contradicciones, porque la represión del crimen y las funciones educativas de las normas penales no escapan a la práctica misma de la jurisprudencia. Superar el enfoque empírico, individual y neutral de la dogmática penal, específicamente, a través de un pensamiento sistémico jurídico que inserte la regla jurídica en una totalidad sistémica de principios racionales (fundamentalmente la peligrosidad social) es un eje imprescindible para la práctica jurídica.

La sociedad global actual demanda analizar la ciencia del Derecho Penal (incluyendo su objeto obviamente) desde la prospectiva de los ordenamientos complejos y sistemas dinámicos. Esto no exonera la teoría de la práctica, sino que plantea un sistema jurídico-penal precedido por un fundamento racional que no limita la dogmática al cuadro normativista. En esta posición no se separa el sujeto teórico del sujeto político. Semejante prospectiva está muy distante del esquema imperante que prioriza la legislación como el instrumento básico del derecho positivo y relega a una función secundaria y subalterna a múltiples contradicciones y mecanismos sociales.

La base conflictual debe convertirse en objeto tanto de la Teoría del Derecho como de la ciencia del Derecho Penal, para alumbrar al sujeto de la política o a los legisladores concretamente. Solamente le importa al positivismo la norma jurídica y la sanción correspondiente o, en su caso, las consecuencias jurídicas. Esto conduce a desatender un proceso tan esencial como la motivación de los sujetos implicados, la cual es condición de la cualidad de la información producida por ella. Es paradójico que en su afán de control y seguridad social, el positivismo penal nunca se interesara por la cualidad del conocimiento producido por el sujeto estudiado.

El enfoque sistémico permite dejar espacio para el desarrollo de nuevas formas constitutivas de la realidad social, las cuales necesariamente se transformarán en momentos del desarrollo del individuo en diferentes subsistemas sociales. La individualidad es

Facultad de Derecho y Ciencias Sociales - Universidad de Valparaíso - Chile 
premisa imprescindible en los sistemas de seguridad jurídica y de igualdad, pues no debe ningún poder actuar en representación de un proyecto en el que realmente no están representados los sectores mayoritarios de la sociedad. El pensamiento sistémico jurídico asume a la dogmática penal como subsistema abierto y no ignora las necesidades del sujeto que están relacionadas con el proceso de autoorganización de su subjetividad.

La reorganización antropológica postulada choca con la lógica kelseniana. El Derecho debe estar urgido de una relación multidisciplinaria que legitime las complejas categorías con las que ha debido contar desde hace mucho tiempo. Si estas categorías, específicamente, la seguridad jurídica y la igualdad que revelan la finalidad básica del Derecho no dan cuenta sobre los procesos ocurrentes en la sociedad dentro de un marco holístico que permita su explicación, jamás serán poseedoras, a su vez, del carácter dinámico, complejo y heterogéneo de la sociedad.

El Derecho, en cuanto sector de la sociedad o de la cultura, se muestra como una realidad, muy compleja, con múltiples y difíciles recovecos, con conexiones muy profundas con la ética, con la moral, con la filosofía, con la ideología, de ahí que sea un subsistema abierto. Sin dudas que el subsistema Derecho no es un fenómeno homogéneo, lineal, definido desde alguna de sus categorías. Este error ha conducido al normativismo todavía dominante en el mundo, a reducir el Derecho a norma dentro de una lógica rígida. Independientemente de que las categorías seguridad jurídica e igualdad son pretendidas realizaciones básicas del Derecho, no se deben estratificar. La integración del Derecho Penal a las ciencias sociales en la construcción teórica de los problemas de igualdad y seguridad jurídica como subsistemas del sistema de la sociedad no implica su subordinación a estas ciencias. Por ser una disciplina propia institucionalizada académicamente, no le amerita aislar la especificidad de los problemas que aborda.

El estudio, enseñanza, interpretación, sistematización en torno a las normas demanda de la construcción teórica compleja. La interrelación entre la subjetividad social y la individual es compleja y contradictoria. El comportamiento del individuo se da en la contradicción entre sus necesidades individuales y sociales, allí atribuye sentido

Revista de Ciencias Sociales - Número 63 (2013) - Universidad de Valparáíso - ISSN 0716-7725-Valparáiso, Chile 
a su desarrollo personal en medio de la colectividad. Así, el Derecho Penal debe tener presente las configuraciones individuales de aquellas acciones de transformación social en la opción de cambio, aunque es obvia la imposibilidad de homogeneizar cada una de las expresiones particulares.

\section{Integración de la ciencia del Derecho Penal}

La interrelación ciencia del Derecho Penal-dogmática penaldelito tiene un carácter histórico. La sociedad es previa al hecho que considera dañoso, peligroso, etc, por tanto, todo principio jurídico-penal porta una ideología de un sujeto histórico determinado. La ideología justifica el porqué de la existencia de un pensamiento, y este es anterior a cualquier formulación normativa de principios. Así, las contradicciones entre los nobles ingleses y la monarquía de Juan sin Tierra en 1215 determinaron el artículo 39 de la Carta Magna: "Ningún hombre libre será detenido, preso, o desposeído, o, proscrito, o muerto en forma alguna; ni podrá ser condenado, ni podrá ser sometido a prisión, si no es por juicio de sus iguales y por las leyes de la tierra".

Aquel precepto inglés, después de pasar por determinadas fundamentaciones, llegó hasta los iluministas burgueses revolucionarios del siglo XVIII: Montesquieu, Rousseau y Beccaria, principalmente. Ellos ilustraron la Revolución Francesa de 1789, sobre todo Beccaria a un nivel más sistemático y teórico. Este principio se consagró en el artículo 8 de la Declaración de los Derechos del Hombre y del Ciudadano de aquel año: "La ley no puede establecer más que penas estrictas y evidentemente necesarias y nadie puede ser castigado sino en virtud de una ley establecida y promulgada con anterioridad al delito y legalmente aplicada". La codificación penal y el constitucionalismo modernos posteriormente recogieron ese principio.

Beccaria teorizó el principio nullum crimen, nulla poena sine lege antes de la codificación penal positivista. La necesidad histórica determinó su plasmación normativa y, luego estimuló a la ciencia del Derecho Penal. El carácter histórico de este principio revela tres sujetos sobre los cuales ha habido más infructuosos intentos de determinarlos e interrelacionarlos que avances en ese sentido. Ellos son: el sujeto de

Facultad de Derecho y Ciencias Sociales - Universidad de Valparaíso - Chile 
la política criminal, el sujeto de la ciencia del Derecho Penal y el sujeto de la dogmática penal.

El Derecho Penal moderno tiene su origen en los principios de la época de las luces. El Iluminismo fue una actitud de pensamiento radical en los albores de lo que después se dio en llamar Revolución Francesa. La razón se convirtió en el tribunal de todo lo existente. El centro de ataque estuvo dirigido al poder monárquico absolutista.

El enciclopedismo sostuvo la defensa del Derecho natural frente a la norma jurídica del poder monárquico. Se trataba de los derechos y libertades inalienables del hombre. El contrato social justificó la organización del Estado. El Estado civil fue un hecho de libertad y preservación de la paz, las cuales ya no podían mantenerse en las condiciones del estado de naturaleza. Por eso, entonces, es delincuente quien se coloca en contra del contrato social, es un traidor en tanto que rompe el compromiso de organización, producto de la libertad originaria o natural; deja de ser miembro de la organización y debe ser tratado como un rebelde ${ }^{20}$. Los postulados del pensamiento racionalista iluminista equiparan a todos los hombres responsabilizándolos por igual de la conservación del pacto implícito en el contrato social. La facultad que tiene cada hombre de posibilitar la convivencia pacífica en la sociedad mediante el respeto de los bienes de cada uno proviene de su capacidad de raciocinio libre. Todo individuo es un ser libre e igual a los demás por obedecer a los mismos dictados de la razón.

De esta ideología liberal del pacto social, en la que el individuo es el valor supremo, se desprende una consecuencia política de mayor importancia con relación al nuevo orden social creado por la voluntad de los ciudadanos libres: por el pacto social los ciudadanos aceptan libremente sujetarse a las normas de igualdad y de restricción para crear y conservar el orden social. El ciudadano acepta también someterse a la ley que ha sido justamente creada por él para que le defienda y proteja este orden social. Con el liberalismo utilitarista esta aceptación del orden uniformiza a todos los individuos dando nacimiento al consenso social. 20. Al respecto véase a ROUSSEAU, Juan Jacobo: El contrato social, Editorial
Taums, Madrid, 1966.

Revista de Ciencias Sociales - Número 63 (2013) - Universidad de Valparáíso - ISSN 0716-7725-Valparaíso, Chile 
El individuo que ataque ese orden, es decir, que infrinja el pacto social, se aparta de las reglas del consenso y por ello entra en otra esfera social, aquella que se encuentra controlada por la nueva ley penal cuya fuerza coactiva proviene del poder punitivo del Estado por voluntad del pueblo. Justamente porque no deja de ser libre, este individuo es totalmente responsable de su acto. Así, la ciencia deja de ser la servidora de la teología, se emancipa y, el Estado y el derecho positivo son llevados ante el tribunal de la razón crítica del hombre.

El fundamento de la intervención penal reside, según Cesare Beccaria (principal representante del Iluminismo en materia penal), en la necesidad de la vida humana asociada, la misma "[...] que constriñó a los hombres a ceder parte de la propia libertad [...]"21 para salir del estado de naturaleza. Ahora el hombre no es el lobo del hombre. El hombre es limitado por la norma penal, la misma que impide un daño mayor y, sólo así es justificada. El castigo tiene la función de la prevención general y no atormentar y afligir como hacían la Inquisición y el régimen monárquico. La exigencia de legalidad de los delitos y las penas como requisito de la seguridad jurídica son los aspectos más conocidos y trascendentes de Beccaria.

La acción u omisión es delito si es un hecho típico "[...] entendiéndose por tal el que incluye todos los elementos que integran la figura creada por la ley, el que reproduce el esquema legal"22. Señala, por su parte, Enrique Bacigalupo:

[...] Que una acción es "típica" o "adecuada a un tipo penal" quiere decir que esa acción es la acción prohibida por la norma. La teoría del tipo penal es, consecuentemente, un instrumento conceptual para la identificación del comportamiento prohibido. La acción ejecutada por el autor es la acción prohibida por la norma cuando se subsume bajo un tipo penal ${ }^{23}$.

21. BECCARIA, Cesare: De los delitos y las penas, Madrid, 1974. (Trad. Tomás y Valiente). Pág. 73.

22. Ibíd. Pág. 335.

23. BACIGALUPO, Enrique: Manual de Derecho Penal. Parte General, Editorial Temis S. A. Colombia, 1996. Pág. 80.

Facultad de Derecho y Ciencias Sociales - Universidad de Valparaíso - Chile 
De esta coincidencia se desprende el concepto de tipicidad. Significa que la dogmática penal posee una base científica. De este modo se consigue revelar el vínculo entre la codificación y la ciencia del Derecho Penal. Es innegable el desarrollo teórico que alcanzó esta materia con la promulgación precedente de legislaciones penales en Occidente: Austria (1852), Suecia (1864), Alemania (1871), Hungría (1878), Holanda (1881), Portugal (1886), Italia (1889). La codificación penal y el positivismo filosófico expresaron una ruptura con el derecho natural. Particularmente, el positivismo jurídico elaboró una concepción del delito a partir del último tercio del siglo XIX fundamentalmente.

Tres concepciones resaltan: la teoría del hombre delincuente de Lombroso, la teoría del delito natural de Garófalo de una parte, y de otra, la de Ferri; por último, la concepción dogmático-formal del delito. La base positivista de este último a tono con el ademán cientificista permitió irrumpir en los fundamentos contractualistas de Rousseau, Montesquieu y Beccaria, quienes no individualizaron el sujeto comisor del delito, a partir del atavismo o cualquier característica sicobiológica. Sus presupuestos teóricos se plasmaron en el artículo 5 de la Declaración de 1789: "Las leyes no tienen el derecho de prohibir nada más que las acciones nocivas a la sociedad".

Entiéndase que la sociedad es la de los ciudadanos, convertidos como tal, debido a la salida del estado de naturaleza y, por consecuencia, el nacimiento contractual del Estado civil, según el liberalismo clásico burgués revolucionario de los siglos XVII y XVIII. Ya el concepto de delito natural dado por Garófalo es sustancialmente ajeno al liberal clásico. El delito natural para él consiste en "[...] la violación de los sentimientos altruistas de la piedad y de la probidad, según la medida media en que se encuentran en la humanidad civil, por medio de acciones nocivas a la colectividad" 24 .

Los rasgos sociológicos del delito que propugna Ferri basándose en la sociología positivista también difieren de la concepción clásica liberal de sociedad y de delito: "Las acciones punibles (delitos) son aquellas que, determinadas por móviles individuales y antisociales, turban las condiciones de existencia y chocan con la moralidad media

24. GARÓFALO, Rafael: Criminología, Bocca editor, Turín, 1885. Pág 2.

Revista de Ciencias Sociales - Número 63 (2013) - Universidad de Valparáíso - ISSN 0716-7725-Valparáiso, Chile 
de un pueblo en un momento dado" 25 , sin embargo, es un concepto antropológico de vocación integradora del sujeto. Plantea que el método positivo es el método del Derecho Criminal: "Las ciencias tienen todas un fondo común y un fin idéntico, a saber: el estudio de la naturaleza y el descubrimiento de sus leyes en provecho de la humanidad"26.

En definitiva, la concepción dogmática formal del delito se ha impuesto en la dogmática penal. Renovar la ciencia del Derecho Penal también desde la Ilustración permitiría aprehender el verdadero sentido del método antropológico, el cual se entiende solamente en contraste con el método científico-naturalista del positivismo dogmático formal. La crisis de la dogmática penal pasa por una crisis práctica del determinismo naturalista atávico del estado peligroso ${ }^{27}$. Sería el cambio de una racionalidad físico-cientificista, que explica el mundo, incluso los problemas humanos y sociales, a partir de un reduccionismo sociologista; por una racionalidad antropológica, que pone en primer plano las necesidades humanas, el destino del hombre, los problemas de su existencia concreta. El cambio de método es, intrínsecamente, un desplazamiento del objeto del conocimiento: del mundo físico del estado peligroso se transita al mundo humano o del objeto hombre.

El hombre deja de ser asumido solo en su existencia corporal, para convertirse en un ser histórico-cultural, enclavado en una

25. FERRI, Enrico: Sociología Criminal, Nueva Biblioteca Universal, Madrid (s/ f). (Trad. Antonio Soto Hernández). Pág. 97.

26. Ibíd. Pág. 11.

27. Para el positivismo jurídico el hombre no se debe al libre albedrío, sino al de las leyes de la evolución natural. De la libre voluntad se pasa a la sujeción natural. El Derecho Penal no reprocha los órdenes morales quebrantados, no es su objeto. El hombre se debe, a su vez, a la norma penal, porque vive en sociedad. El libre albedrío se trueca en responsabilidad social, cuyas exigencias es la defensa del organismo social. Por tanto la norma penal subordina al sujeto sin relación alguna con los impulsos de su ser moral. La defensa de la sociedad requiere la retribución por el delito y la prevención del delito. La acción cometida no es lo central del Derecho Penal, 27 sino la peligrosidad del sujeto, su pronóstico como futuro autor de delitos. Se trata del sujeto al que se considera peligroso según pautas atávicas y determinativas de su peligrosidad.

Facultad de Derecho y Ciencias Sociales - Universidad de Valparaíso - Chile 
problemática vital concreta de sus derechos fundamentales, que es preciso conocer y explicar. Los derechos fundamentales derivados de la dogmática penal son formulados como facultades o capacidades de las que son titulares individuos o grupos humanos, con la implicación que esto trae de complejidad agregada a la hora de pensar los diferentes grados de tutela que los mismos reciben. La ambigüedad del término es amplia, y se da una singular pluralidad de conceptos que dependen de los contextos referentes al sistema normativo desde el cual se plantee.

La expresión normativa, dado el caso específico de los derechos fundamentales formulados como norma jurídico-penal, se constituye en entidad estructurante institucional y procedimental de la praxis política; a su vez la política actualiza las hipótesis jurídicas, la que suministra los contenidos a la formulación de lo que se entiende por derechos fundamentales. Este momento exige una necesaria integridad analítica y crítica de la ciencia del Derecho Penal en cuanto a la capacidad de la dogmática penal de reflejar la subjetividad y su actividad transformadora de la base conflictual más allá de cualquier status de conciliación falsa. Para Ronald Dworkin, el legislador crea un derecho positivo coherente con la estructura de principios que fundamentan la existencia de esta práctica social. La crítica reconoce la base conflictual de la sociedad que engendran diversas prácticas, el derecho positivo es resolución de conflictos, pero no se limita a puras reglas puesto que se cohesiona con principios y no absolutamente con la pura norma. Se establece así una interrelación entre racionalidad de la decisión, principios y la práctica social.

Dicha propuesta tiene el sentido siguiente: el jurista, previamente, señala cuáles son las normas jurídicas vigentes creadas por el legislador, pero se le es imprescindible la búsqueda y establecimiento de consecuencias a partir de los principios. El derecho positivo o la dogmática penal en el caso que ocupa este trabajo no sólo se reduce a la regla que debe aplicarse, es decir, cualquier intérprete tiene la misión de seguir aquellas razones que tengan más peso a la luz del propósito de la práctica en su conjunto, obteniendo la conclusión jurídica que permita presentar esta práctica social desde su mejor perspectiva. Para Dworkin, si un intérprete asume el ideal de la integridad y reflexiona lo suficiente, si se toma los derechos verdaderamente en serio, siempre podrá identificar

Revista de Ciencias Sociales - Número 63 (2013) - Universidad de Valparáíso - ISSN 0716-7725-Valparáiso, Chile 
la respuesta jurídica correcta. Considera, además, que el modelo de los principios posibilita, de un lado, encontrar soluciones jurídicas a supuestos no resueltos por las reglas y, de otro lado, justificar, en ciertos casos, la transformación de las reglas cuando el resultado de aplicarlas se aleje demasiado del esquema de principios que las justifica ${ }^{28}$.

Su crítica enfrenta directamente al postulado que constituye la pureza de la teoría kelseniana: la ciencia jurídica, como ciencia que es, sólo puede conocer o describir el derecho positivo, no valorarlo. No obstante, la función de aplicar el derecho positivo es compleja y resulta extraño transformar en la inmediatez la regla cuando se aleja del principio que la fundamenta. Esta labor debe corresponder al legislador, sólo que tendría que romper con esquemas; uno de ellos es precisamente asumir la teoría de Dworkin. El legislador debe hacer suyos los principios para una mejor racionalidad y qué decir de los jueces fundamentalmente. Es una imperiosa necesidad trascender la formalidad de la legitimidad y la eficacia. Se trata de rebasar la estrecha fundamentación que parte del criterio de que es suficiente con que el órgano facultado apruebe la norma jurídica para que se considere legítima. La práctica social y la voluntad popular expresada por necesidad de cambio dirá la primera palabra en relación a su eficacia y, en tal sentido no carente de objetividad, constituirá un resorte medidor.

\section{Conclusiones}

El reconocimiento de la contradicción especial, en la dogmática penal, como forma específica de presentarse la contradicción de la ciencia del Derecho Penal permite no confundir la construcción del conocimiento con el objeto real. El positivismo jurídico no destaca la centralidad del hombre alrededor del cual debe girar el sistema categorial. Un determinismo, en este caso positivista, es reducir el Derecho como norma y ente abstracto exclusivo de sí mismo.

El internalismo epistemológico iuspositivista sobrevalora los factores lógico-metodológicos en detrimento de los factores externos

28. Al respecto véase a DWORKIN, Ronald: A Matter of Principle, Harvard University Press, Cambridge, 1985.

Facultad de Derecho y Ciencias Sociales - Universidad de Valparaíso - Chile 
que influyen sobre el sujeto cognoscente. La antropología jurídicopenal, por su parte, viabiliza metodológicamente la aprehensión sistémica de una racionalidad integradora de la intervención subjetiva y la actividad transformadora del hombre al unificar en lo diverso las varias dimensiones del quehacer práctico-espiritual del sujeto cognoscente: las expresiones ontológica, lógica, gnoseológica, valorativa, praxiológica, comunicativa y normativa. Esto indica una dinámica de la ciencia del Derecho Penal como proceso histórico de investigación abierto a la transformación creativa de las teorías y los métodos en favor del cambio.

El antropologismo jurídico-penal asume el hombre y su esfera de valores como objetos del Derecho Penal. Pone en duda a la neutralidad iuspositivista y se convierte en correctivo legal y social con el cual la revisión de la dogmática penal expande el ideal de justicia. La definición de antropologismo jurídico, por el camino del pensamiento crítico, conduce a la reproducción del objeto hombre con el cual el sujeto cognoscente sienta las bases metodológicas para determinar, argumentar, explicar y valorar el concepto antinormativista de Derecho Penal. La antropología jurídico-penal rechaza los presupuestos teóricos y dogmáticos positivistas que subyacen en la ciencia del Derecho Penal, estos son: la determinación del delito a través de conceptos físicos, atávicos y biológicos sustentada por la escuela de la política criminal de Von Liszt, la teoría de las normas de Karl Binding, la teoría del tipo de Ernest von Beling.

Von Liszt y Beling son máximos representantes del concepto dogmático-formal del delito. Técnicamente, el estado peligroso se observa como contenido de la responsabilidad penal y no el hecho que resulta socialmente peligroso, la necesaria defensa social que postula Ferri es sustituida por la peligrosidad del sujeto.

La antropología jurídico-penal toma al hombre como un ser histórico-cultural, dentro de problemáticas vitales concretas de sus derechos fundamentales formulados como normas jurídico-penales, y entidad estructurante institucional y procedimental de la praxis política, que es justo conocer y explicar. La ciencia del Derecho Penal, en consecuencia, debe ser crítica ante la capacidad de la dogmática penal de reflejar la subjetividad y la actividad transformadora de la base 
conflictual tanto del sujeto cognoscente como del objeto hombre. En este caso, resulta apropiado el teórico Ronald Dworkin, porque considera que el legislador construye un derecho positivo afín con la estructura de principios derivados de la práctica social. Esta posición reconoce la base conflictual de las prácticas sociales donde el derecho positivo es resolución de conflictos y no pura regla. Se establece así una interrelación entre racionalidad de la decisión, principios y la práctica social. El sujeto del conocimiento no neutraliza su subjetividad por ende, promueve el consenso de todo sujeto racional a compartir las teorías, los procedimientos y las técnicas.

\section{Bibliografía}

ATIENZA RUIZ, José: Las piezas del Derecho. Teoría de los enunciados jurídicos, Ariel, Barcelona, 1996.

BACIGALUPO, Enrique: Manual de Derecho Penal. Parte General, Editorial Temis S. A. Colombia, 1996.

BARATTA, Alessandro: Criminología crítica y crítica del Derecho Penal. Introducción a la sociología jurídico-penal,

BECCARIA, Cesare: De los delitos y las penas, Madrid, 1974. (Trad. Tomás y Valiente).

BELING, Ernst von: Esquema de Derecho Penal. La teoría del delitotipo, Bs. As. Depalma, 1944. (Trad. S. Soler).

Siglo XXI Editores Argentina s. a. Buenos Aires, 2004.

DURKHEIM, Emile: Las reglas del método sociológico, Editorial A Kal, Madrid, 1997.

DWORKIN, Ronald: A Matter of Principle, Harvard University Press, Cambridge, 1985.

FERNÁNDEZ BULTÉ, Julio: Filosofía del Derecho, Editorial Félix Varela, La Habana, 2003

FERRI, Enrico: Principios de derecho criminal, (s/p/i), 1928.

FERRI, Enrico: Sociología Criminal, Nueva Biblioteca Universal, Madrid (s/f). (Trad. Antonio Soto Hernández).

GARÓFALO, Rafael: Criminología, Bocca editor, Turín, 1885.

KELSEN, Hans: ¿Qué es la Teoría pura del Derecho? Fontamara, México, 1993. (Trad. de E. Garzón Valdés).

Facultad de Derecho y Ciencias Sociales - Universidad de Valparaíso - Chile 
QUIRÓS PÍREZ, Renén: Manual de Derecho Penal, tomo I, Editorial Félix Varela, La Habana, 2006.

RAMOS, Guadalupe: Derecho Penal. Parte General I, Facultad de Derecho, Universidad de La Habana, 1985.

ROUSSEAU, Juan Jacobo: El contrato social, Editorial Taums, Madrid, 1966. 